\title{
Antioxidant Vitamin (E\&C) Contents in Colostrum of Bangladeshi Women
}

\author{
Rubena Haque1, Shahnila ferdousi², Sk Nazrul Islam³, \\ Razia Sultana 4 , Shammi Sultana Ferdousi 5
}

\begin{abstract}
Background: Colostrum is the first product of lactation and can be considered as first vaccine for newborns. It contains numerous nutrients as well as antioxidant vitamins necessary for newborns. Objective: The aim of the study was to measure the antioxidant vitamin (vitamins $E$ and $C$ ) contents in colostrum and to compare them with the nutritional status, age and parity of the lactating mothers and birth weight of the babies. Materials and method: In this cross sectional study antioxidant vitamins $E$ and $C$ of colostrum of seventy six post-partum mothers were estimated irrespective of their age, parity, socioeconomic and nutritional status. High Performance Liquid Chromatography (HPLC) was employed to analyze the colostral content of vitamin $E$ and spectrophotometric method was used for estimation of vitamin $C$ (ascorbic acid) level. These levels were then compared against maternal and fetal characteristics. Results: The mean concentration $( \pm S D)$ of vitamin $E$ and $C$ were $519.809( \pm 1.16) \mu \mathrm{gm} / \mathrm{dl}$ and $1.33( \pm 0.076) \mathrm{mg} / \mathrm{dl}$ respectively. No significant relationship was found between maternal age, parity, BMI or birth weight of the baby and the colostral content of vitamin $E$ and C. Conclusion: Colostrum of Bangladeshi women are rich in antioxidant vitamins and not dependent on sociodemographic variables of mothers and / or birth weight of baby.
\end{abstract}

Keywords: Human colostrum; antioxidant vitamins.

Delta Med Col J. Jul 2014;2(2): 53 - 57

\section{Introduction}

Colostrum (also known as beestings or first milk) is a form of milk produced by the mammary glands in late pregnancy and few days after birth of a child. It is translucent, deep lemon yellow in colour, alkaline in reaction. The distinct yellow colour is due to presence of carotenoids in its fat globules. ${ }^{1}$ Colostrum is considered as a package of essential nutrients (vitamins, minerals, essential fatty acids and essential amino acids) and is commonly known as the best kind of nutrition for neonates. The effect of human colostrum on promoting body growth and development is stronger than that of mature milk.
In addition of numerous clinical significance of breast feeding it seems human milk has bioactive components that protect newborns from a hyperoxic challenge due to transition of life to an environment for richer in oxygen than intrauterine environment. ${ }^{2-4}$ Oxygen is potentially toxic, because of the production of reactive oxygen species (ROS). Since these compounds have the ability to interact with and alter essential cell molecules, they are extremely cytotoxic. Antioxidant defense mechanisms of the body may prevent the production of ROS or neutralize them. 5 When the production of

1. Assistant Professor, Department of Biochemistry, Sir Salimullah Medical College, Dhaka, Bangladesh.

2. Associate Professor, Department of Biochemistry, Dhaka Medical College, Dhaka, Bangladesh.

3. Professor, Institute of Nutrition and Food Science, University of Dhaka, Bangladesh.

4. Assistant Professor, Department of Biochemistry, Delta Medical College, Dhaka, Bangladesh.

5. Indoor Medical Officer, Department of Gynae \& Obs, Sir Salimullah Medical College, Dhaka, Bangladesh.

Correspondence: Dr. Rubena Haque. e-mail: rubenahaque@gmail.com 
ROS exceeds the capacity of the body's antioxidant defense to detoxify them, a condition known as oxidative stress occurs.

Colostrum contains high content of antioxidant vitamins (E \& C). Vitamin E consists of a group of tocopherols. There are eight naturally occurring tocopherols, of these $\alpha$-tocopherol has the greatest biological activity. Colostrum contains several times as much as tocopherol as mature milk. So a large supply of vitamin E during the first week of life is possible by colostrum. 6 The major function of vitamin $E$ is that it has role as scavenger of free radicals, preventing free radicals or oxidative damage to polyunsaturated fatty acid in cell membrane, thiol rich protein constituents of membranes, cytoskeleton and nucleic acid. Vitamin $\mathrm{E}$ is one of the primary factors in these defense mechanisms because of its lipid solubility and therefore can directly protect cell membrane. $7-8$

Vitamin $\mathrm{C}$ is also known as ascorbic acid, ascorbate or ascorbate monoanion. As it loses electron easily, it is a good reducing agent for intra- and extracellular biochemical reactions. Ascorbate reduces superoxide, hydroxyl radical, hypochlorous acid and other reactive oxidants. These oxidants may affect DNA transcription or could damage DNA, proteins or membrane structures, ascorbate may have a central role in cellular oxidant defense.9-10 Outside the cells, ascorbate may prevent low density lipoprotein oxidation. ${ }^{11}$ Extracellular ascorbate also transfers electron to tochopherol radicals in lipid particles or membranes. 12

It is well-believed that oxidative stress is involved in the pathogenesis of numerous neonatal diseases, such as bronchopulmonary dysplasia, retinopathy of prematurity and necrotizing enterocolitis. ${ }^{13-14}$ High antioxidant capacity in colostrum can be effective in preventing newborns from exposure to an environment rich in oxygen after birth, 4 to 5 times as much as intrauterine environment. 4 There is some evidence that susceptible newborns, especially preterm ones, are potentially vulnerable to oxidative stress due to the inefficiency of their antioxidant defense system or increase in free radical production. 15 In this situation damage to main molecules, lipids, proteins, carbohydrates and nucleic acids may increase. 16 Human milk has a number of enzymatic and nonenzymatic antioxidant constituents like superoxide dismutase, glutathione peroxidase, catalase, vitamin $\mathrm{E}$, vitamin $\mathrm{C}$, $\beta$-carotene which may protect newborns against ROS at the early stage of life. However, for the best benefits and functions, milk will always be recognized as a synergistic mixture of multiple interacting factors. Colostrums in comparison to transitional and mature milk has more total antioxidant activity that decreases during the course of lactation. 17

The importance of colostrum feeding is immense for its diverse functions. It is of no doubt that colostrum fed infants are less susceptible to respiratory and gastrointestinal infections.

Bangladesh is a developing country and still is fighting against malnutrition and infection to which new born infants and children are more susceptible and till now infant mortality due to diarrhea, respiratory tract infections and malnutrition is prevalent in our country. Colostrum itself can play a vital role in this context. The study was carried out to measure the antioxidant vitamin contents in colostrum in our setting and to determine the relationship of them with the nutritional status, age and parity of the lactating mothers and birth weight of the babies.

\section{Materials and method}

This cross sectional study was conducted amongst seventy six postpartum mothers who delivered their babies at the Maternity and Child Health Training Centre, Azimpur, Dhaka, Bangladesh. Mothers (delivered per vagina or by cesarean section) were selected randomly irrespective of their socio-economic status, educational qualification, age and parity. All the study subjects were free of any kind of complication. After having deliberate consent, they were considered as participants. $2 \mathrm{~mL}$ colostrum was collected by hand expression into an acid washed screw capped $5 \mathrm{ml}$ glass vial on the 2 nd postpartum day during their stay in the postnatal ward. Privacy of the mothers was strictly maintained. Anthropometric data and relevant information of mothers as well as birth weight of the babies were recorded in predefined data sheet. 


\section{Colostral analysis:}

Colostrum specimens were preserved at $-200^{\circ} \mathrm{C}$ for analysis. $0.8 \mathrm{ml}$ of colostrum was taken for further treatment with tricarboxylic acid (TCA) on the day of collection for vitamin $\mathrm{C}$ analysis.

Reversed phase HPLC (LC-10AD, SHIMADZU, HPLC 1991, Model-7125, Japan) was used for estimation of $\alpha$-tocopherol (vitamin E) in the colostrum.

The concentration of ascorbic acid in the colostrum was determined by spectrophotometric method using phenyl hydrazine indicator (Sigma Chemical Co., USA) as described by Islam et al. 18 Absorbance was measured against a reagent blank at $520 \mathrm{~nm}$ by a spectrophotometer (UV-1201, UV-VIS), Shimadzu, Japan.

Data were analyzed by using the software SPSS 12.0 for windows. Values were expressed as percentage and mean values of different subgroups were compared by independent Student ' $t$ ' test and one way ANOVA.

\section{Results}

Total 76 mothers and their babies were included in this study. The mean maternal age was $24.22( \pm 0.62)$ years.

Maternal characteristics of the study population are shown in Table I. Most of the mothers (63.2\%) were young (19-25 years) having normal BMI (18.5 - 25) and were primi parae. Most of the babies were healthy. Only $13.2 \%$ were found as low birth weight (LBW).

Table l: Maternal characteristics and birth weight of babies

\begin{tabular}{cccc}
\hline Characteristics & Variables & Frequency & Percentage \\
\hline & Age group (years) & & \\
& Upto 18 & 13 & 17.1 \\
& $19-25$ & 33 & 43.4 \\
\multirow{4}{*}{ Mother } & $\geq 26$ & 30 & 39.5 \\
& Parity & & \\
& Primipara & 48 & 63.2 \\
& Multipara & 28 & 36.8 \\
& BMI & & \\
& $<18.5$ & 7 & 17.1 \\
& $18.5-25$ & 45 & 59.2 \\
& $>25$ & 24 & 31.6 \\
Baby & Birth weight of the baby $(\mathrm{Kg})$ & & \\
& $<2.5$ & 10 & 13.2 \\
& $2.5-2.99$ & 27 & 35.5 \\
& $\geq 3$ & 39 & 51.3 \\
\hline
\end{tabular}

Mean concentration of antioxidant vitamins in colostrum is shown in Table II. The concentrations of vitamin $\mathrm{E}$ and $\mathrm{C}$ were found $519.81( \pm 1.16) \mu \mathrm{g} / \mathrm{dl}$ and $1.33( \pm 0.08) \mathrm{mg} / \mathrm{dl}$ respectively.

Table II: Vitamin contents in colostrum

\begin{tabular}{lcc}
\hline $\begin{array}{l}\text { Antioxidant } \\
\text { vitamins }\end{array}$ & Mean \pm SD & Range \\
\hline Vitamin E $(\mu \mathrm{g} / \mathrm{dl})$ & $519.81 \pm 1.16$ & $508.86-573.75$ \\
Vitamin $C(\mathrm{mg} / \mathrm{dl})$ & $1.33 \pm 0.08$ & $0.13-3.03$ \\
\hline
\end{tabular}

Table III shows the comparison of colostral antioxidant vitamins with maternal and baby's characteristics. No significant relationship was found with maternal age, parity, BMI and birth weight of babies.

Table III: Comparison of colostral antioxidant vitamins with maternal characteristics and birth weight of the baby.

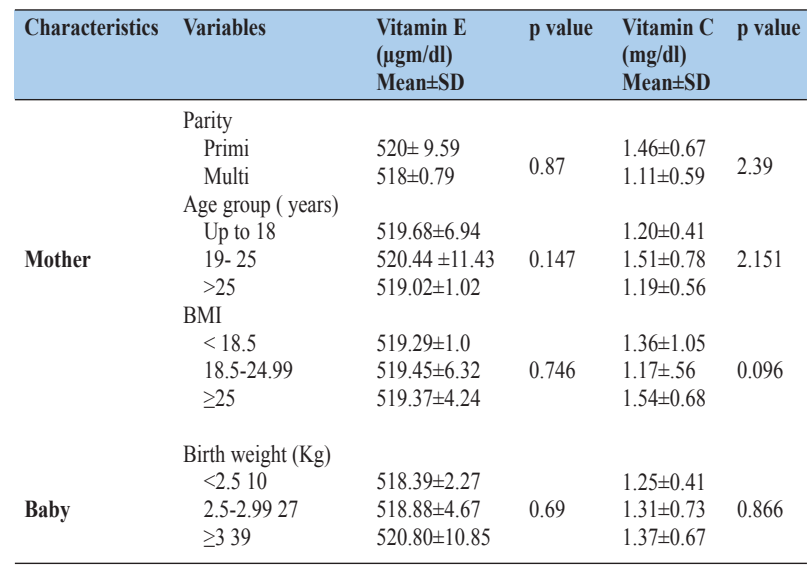

\section{Discussion}

In this study, the concentration of vitamin $\mathrm{E}$ and vitamin $\mathrm{C}$ in colostrum of Bangladeshi mothers were estimated. Majority of the mothers were primipara of normal reproductive age group. The colostral content of vitamin $\mathrm{E}$ was found to be much higher than the values reported for milk19,20 but the result is consistent with the concentration claimed for colostrum. ${ }^{21}$

Concentration of vitamin $\mathrm{C}$ in the colostrum was similar to those reported in different studies done in Bangladesh21,24 but the value is lower than those reported for developed and developing countries.22-23 Comparison of antioxidant (vitamins E \& C) concentration with different 
maternal characteristics (age, parity and BMI) was done but statistical significance could not be ascertained which is in line with the study done by Islam et al. ${ }^{21}$ We obtained from the study that antioxidant vitamin contents of colostrum do not depend on maternal age, parity, nutritional status of mothers or even birth weight of the baby. Nature protects the weak newcomers by colostrum as like as healthy ones. Hence newborn feeding with the breast milk especially colostrum can be useful to neutralize free radicals and improve antioxidant system of the baby.

It is to be concluded that colostrum of a group of Bangladeshi women is rich in antioxidant vitamins which is independent of nutritional status, age or parity of mothers and plays an important role in the growth, development and immunity of infant's life. This finding is of considerable clinical and public health significance. Promotion of colostrum feeding will ensure child survival, growth and development irrespective of socioeconomic status of the parents and even a drop of colostrum should not be discarded.

\section{References}

1. Patton S, Canfield LM, Huston GE, Ferris AM, Jensen RG. Carotenoids of Human Colostrum. Lipids. 1990;25(3):159-65.

2. Ye S, Sun R, Lu Q. The Study of Growth Factors in Human Colostrum. Zhonghua Fu Chan Ke Za Zhi. 1995;30(10):591-93.

3. Saugstad OD. Bronchopulmonary Dysplasia Oxidative Stress and Antioxidants. Sem in Neonatol. 2003;8:39-49.

4. Friel JK, Friesen RW, Harding SV, Roberts LJ. Evidence of Oxidative Stress in Full-Term Healthy Infants. Pediatr Res. 2004;56:878-82.

5. Tsukahara H. Biomarkers for Oxidative Stress: Clinical Application in Pediatric Medicine. Curr Med Chem. 2007;14:339-51.

6. Jasson L, Akesson B, Halmberg L. Vitamin E and Fatty Acid Composition of Human Milk. Am J Clin Nutr. 1981;34:8-13.

7. Packer L, Kegan VE. Vitamin E: the Antioxidant Harvesting Centre of Membranes and Lipoproteins. In Packer L, Fuchs L, editors. Vitamin E in Health and Disease. New York: Marcel Dekker; 1993.p.179-92.
8. Tappel AL. Vitamin E as a Biological Antioxidant. Vitam Horm. 1962;20:493-510.

9. Frei B, England L, Ames BN . Ascorbate is an Outstanding Antioxidant in Blood Plasma. Proc Natl Acad Sci USA. 1989; 86: 6377-6381.

10. Hallwell B. Free Radicals and Antioxidants: A Personal Review. Nutr Rev. 1994;52:259-65.

11. Jailal I, Grundy SM. Effects of Combined Supplementation with $\alpha$-tocopherol, Ascorbic Acid and $\beta$-carotene on Low Density Lipoprotein Oxidation. Circulation. 1993;88:2780-86.

12. Niki E, Noguchi N, Tsuchihashi G, Gotoh N. Interaction among Vitamin $\mathrm{C}$, Vitamin $\mathrm{E}$ and $\beta$-carotene. Am J Clin Nutr. 1995;62:1322-26.

13. Schelbmmeir HD, Christensen K, Whitaker SH, Jegaethesan J, Clancy R, Pierce JD. A Review of Free Radicals and Antioxidants for Critical Care Nurses. Intensive Crit Care Nurs. 2005;21:24-28.

14. Thompson AM, Bizzarro MJ. Necrotizing Enterocolitis in Newborns: Pathogenesis, Prevention and Management. Drugs. 2008;68:1227-38.

15. Yeung MY. Influence of Early Postnatal Nutritional Management on Oxidative Stress and Antioxidant Defence in Extreme Prematurity. Acta Paediatr. 2006;95:153-63.

16. Tsukahara H, Jiang MZ, Ohta N, Sato S, Tamura S, Hiraoka M, Mayumi M. Oxidative Stress in Neonates: Evaluation Using Specific Biomarkers. Life Sci. 2004;75:933-38.

17. Zarban A, Taheri F, Channhkandi T, Sharifzadeh G, Khorashadizadeh M. Antioxidant and Radical Scavenging Activity of Human Colostrum, Transitional and Mature Milk. J Clin Biochem Nutr. 2009;45(2):150-54.

18. Islam SN, Hossain KJ, Ahsan M. Serum Vitamin E, $\mathrm{C}$ and A Status of the Drug Addicts Undergoing Detoxification: Influence of Drug Habit, Sexual Practice and Lifestyle Factors. Eur J Clin Nutr. 2001;55:1022-27.

19. Barua S, Tarannum S, Nahar L, Mohiduzzaman M. Retinol and $\alpha$-tocopherol Content in Breast Milk of Bangladeshi Mothers under Low Socioeconomic Status. International Journal of Food Sciences and Nutrition. 1997;48:13-18.

20. Jansson L, Akesson B and Halmberg L. Vitamin E and Fatty Acid Composition of Human Milk. Am J Clin Nutr. 1981;34:8-13. 
21. Islam SN, Ahmed L, Khan MNI, Haque S, Haque R, Halim H, Ahsan M. Immunonutrients Constituents of Human Colostrum. Bangladesh Journal of Nutrition. 2004;16:75-82.

22. Newman V. Vitamin A and Breast Feeding: A Comparison of Data from Developed and Developing Countries. San Diego, California, Wellstart International, USAID [Internet]. 1993 [cited 2013 Sept 21]. Available from: http:// www. popline.org/ node/ 334303.
23. Krisksy A, Udipi SA. Analysis of Water Soluble Vitamins in Human Milk: Vitamin B-6 and Vitamin C. In: Jensen RG, Neville MC, editors. Human Lactation. New York: Plenum Press; 1995.p.153-70.

24. Ahmed L, Islam SN, Nahid SN. Vitamin C Content in Human Milk (Colostrum, Transitional and Mature) and Serum of a Sample of Bangladeshi Mothers. Mal J Nutr. 2004;10(1):1-4. 